Article

\title{
Dispersion Stability and Lubrication Performance Correlation of Vegetable Oil-In-Water Emulsions with Nanoparticle-Shielded Oil Droplets
}

\author{
Reza Taheri *, Buyung Kosasih, Hongtao Zhu and Anh Kiet Tieu
}

School of Mechanical, Materials, Mechatronics, and Biomedical Engineering, University of Wollongong, Wollongong 2522, Australia; buyung@uow.edu.au (B.K.); hongtao@uow.edu.au (H.Z.);

ktieu@uow.edu.au (A.K.T.)

* Correspondence: rt795@uow.edu.au

Received: 3 May 2018; Accepted: 6 June 2018; Published: 9 June 2018

\begin{abstract}
Vegetable oil-in-water $(\mathrm{VO} / \mathrm{W})$ emulsions are bio-based metal working lubricants. The emulsions' lubrication performance depends on the stability of oil droplets. In this paper, the oil droplets' dispersion stability and lubrication of emulsions containing $\mathrm{TiO}_{2} / \mathrm{SiO}_{2}$ nanoparticles (NPs) as dispersant and lubrication agents have been investigated. Enhanced dispersion of NP-shielded oil droplets was found. Increasing the NPs' mass fraction initially lowers the average size of NP-shielded droplets up to the saturation of the droplets' surface with NPs at $0.5 \mathrm{wt} \%$ mass fraction. NPs also form NP agglomerates in emulsions, more so after the droplets' surfaces have been saturated with NPs. There is an apparent minimum quantity of NPs $(\sim 0.5 \mathrm{wt} \%)$ required to ensure sustained dispersions of the droplets which is thought to be related to the oil concentration and the droplets' total surface-area-to-volume ratio. Below the required quantity of NPs, partially shielded and fully shielded droplets coexist. The partially shielded droplets initially attract other droplets and undergo limited coalescence but retain their long-term stability. A small quantity of NPs improves the antiwear property of the lubricants. However, emulsions with NPs have slightly higher friction than the NP-free emulsion due to the reduced strength of the tribofilm. Despite the increased friction, the tribofilm formed in presence of NPs can easily be removed from the surface with water, indicating cleaner surfaces after the lubrication (i.e., less oil residue on the surfaces), which, for the sake of cleanliness, is favourable in many applications.
\end{abstract}

Keywords: nanoparticle-induced stability; clean lubrication; bio-based vegetable oil-in-water emulsion; $\mathrm{TiO}_{2} / \mathrm{SiO}_{2}$ composite nanoparticles

\section{Introduction}

Vegetable oil-in-water $(\mathrm{VO} / \mathrm{W})$ emulsions are promising renewable and environmentally friendly metal working lubricants [1]. Polar vegetable oil droplets of $\mathrm{VO} / \mathrm{W}$ emulsions comprise fatty acid triglycerides and have a strong adsorption propensity to metal surfaces, hence, they provide good lubricity in the boundary regime lubrication [2-4]. In order to perform the lubrication role, droplets in emulsions must be in a stable dispersed state. Ultrasonic homogenising has been used to prepare stable droplets in emulsions [5]. However, long-range hydrophobic attraction forces exist between the vegetable oil droplets in $\mathrm{VO} / \mathrm{W}$ emulsions that cause coalescence; hence, the oil/water phase separation occurs over time [5-7]. Surfactants, surface-active polymers, and solid nanoparticles (NPs) have been used to improve the dispersion stability of such emulsions [8]. NPs are particularly more attractive stabilising agents as they possess both dispersant and lubrication properties that can be combined in composite NPs $[9,10]$. 
In NP-stabilised emulsions (known as Pickering emulsions), the stability of droplets is attributed to the presence of steric layers of NPs (NP shields) on the oil/water interface of droplets, similar to egg-shell structures [11,12]. The formation and stability of NP shields on the droplets' surface depends on the shape, size, and mass fraction of NPs (wt \%), as well as inter-NP interactions and adsorption characteristics of NPs on the droplets' surface [10-14]. Formation of dense, closely packed NP shields on the droplets' surface is preferred for better dispersion characteristics. Hence, an adequate quantity of NPs is necessary to ensure the formation of uniform NP shields [13,14]. The required quantity of NPs depends on the NP/oil concentration ratio. A low quantity of NPs results in partial coverage of the droplets with NP shields. By increasing the NPs' mass fraction, NPs continuously accumulate on the droplets' surface and increase the stability of droplets up to a saturation point (adsorption plateau of NPs on the droplets' surface). Above the adsorption plateau of NPs, excess NPs form NP agglomerates in the emulsion that deteriorates the stability [12,15].

On the other hand, inhomogeneous NPs with nonuniform geometries cannot form closely packed NP shields on the droplets' surface. In such cases, partial coverage of droplets with NPs occurs. If giving rise to the repulsive double-layer electrostatic forces between the droplets, such partial coverage with NPs can provide stability [8]. For instance, with particular NPs having ionisable surface groups on the droplets' surface, parts of the NPs that reside in water become ionised $\left(\mathrm{OH}^{-}\right.$formation), charging NPs asymmetrically. The charged NPs on the droplets' surface attract counter-ions from water, create charge fields around the droplets and electrostatically improve the coalescence stability [16]. This makes ionisable NPs such as silica good dispersion agents [13] and common elements in composite NPs with combinative dispersant and lubrication properties.

In addition to dispersing effects, some NPs such as $\mathrm{TiO}_{2}$ show good lubricity in different environments $[17,18]$. To benefit from the synergic lubricity effects of $\mathrm{TiO}_{2} \mathrm{NPs}$ and dispersant effects of $\mathrm{SiO}_{2} \mathrm{NPs}, \mathrm{TiO}_{2} / \mathrm{SiO}_{2}$-composite $\mathrm{NPs}$ were investigated in soybean $\mathrm{VO} / \mathrm{W}$ emulsions. Mechanisms with which the dispersion stability of the soybean oil droplets is provided with $\mathrm{TiO}_{2} / \mathrm{SiO}_{2} \mathrm{NPs}$ are discussed. The stability of emulsions is then correlated with the lubrication properties of the NP-stabilised droplets of the emulsions in the boundary lubrication regime.

\section{Methodology}

\subsection{Materials and Preparation of Emulsions}

$\mathrm{TiO}_{2} / \mathrm{SiO}_{2}$-composite NPs (Sigma Aldrich, Castle Hill, Australia) and soybean oil (Masterolfoods, Whitebridge, Australia) were used. $\mathrm{TiO}_{2} / \mathrm{SiO}_{2} \mathrm{NPs}$ have amorphous structures in which chainlike $\mathrm{SiO}_{2} \mathrm{NPs}$ are incorporated into $\mathrm{TiO}_{2} \mathrm{NPs}$, where $\mathrm{SiO}_{2}$ acts as carrier for $\mathrm{TiO}_{2}[19,20]$. The XRD analysis of $\mathrm{TiO}_{2} / \mathrm{SiO}_{2} \mathrm{NPs}$ indicated the NPs' average size to be $35 \mathrm{~nm}$ [21]. Soybean oil is composed of $15 \%$ saturated, $24 \%$ monounsaturated, and $61 \%$ polyunsaturated fatty acids. VO/W emulsions were ultrasonically homogenised using $0 \%, 0.1 \%, 0.25 \%, 0.5 \%, 0.75 \%$, and 1 wt $\%$ NPs and 1 vol $\%$ soybean oil. Initially, NPs were dispersed in water by 30 min ultrasonication. 1 vol \% oil was then added to the $\mathrm{NP}$ dispersions and emulsions were emulsified with $0.16 \mathrm{~kJ} / \mathrm{mL}$ homogenising energy to ensure the initial production of fine oil droplets with low dispersity [21].

\subsection{Characterisation of NPs and VO/W Emulsions}

Size distributions of oil droplets and NP agglomerates were measured immediately after the preparation (on day 0) and then after 14 and 28 days using a Malvern Zetasizer nano S (Malvern Panalytical, Worcester, UK). The UV-vis spectrophotometry technique was used to study the stability of the droplets after the preparation in the wavelength range of 200-600 nm. Emulsions were diluted in water ( $1 \mathrm{vol} \%$ concentration) and measurements were performed on a Shimadzu UV-1800 spectrophotometer (Shimadzu Corp., Kyoto, Japan). The over-time stability of the emulsions within $96 \mathrm{~h}$ after the preparation is discussed in terms of the ratio of the absorbance intensity at different 
times to the corresponding initial value on day 0 . This indicates the relative concentration $(R C)$ of NPs in the emulsions at different times.

The interactions between NPs and oil droplets were observed using confocal laser scanning microscopy (CLSM) on a Leica TCS SP8 (Leica Microsystems, Mannheim, Germany). To identify NPs, Rhodamine B fluorescence dye (95\%, excitation wavelength $552 \mathrm{~nm}$ ) (Sigma Aldrich) was used [22]. Dye suspension in water $(0.0001 \mathrm{wt} \%$ mass fraction) was used to prepare the emulsions for confocal microscopy analysis. Agglomerates of NPs in the aqueous phase were analysed using Jeol JSM6490 SEM/EDS (Jeol Ltd., Tokyo, Japan).

\subsection{Lubricity of $V O / W$ Emulsions}

The effect of $\mathrm{TiO}_{2} / \mathrm{SiO}_{2} \mathrm{NPs}$ on the friction reducing property of emulsions was investigated using stainless steel SS316 balls (4 mm diameter) and discs on a UMT2 tribometer (Bruker, Billerica, MA, USA). To ensure boundary regime lubrication, lubricity tests were run at $60 \mathrm{rpm}(0.0125 \mathrm{~m} / \mathrm{s})$ under a $6 \mathrm{~N}$ load [23]. Friction tests were designed to assess the film-forming property of emulsions. Initially, water was used as a reference lubricant in stage I for comparison purposes. Water was then replaced with the emulsions in stage II of the tests to assess the film-forming capability of the emulsions by measuring the coefficients of friction (COFs) for $25 \mathrm{~min}$. By further replacing the bulk of emulsions with water, the supply of the oil droplets to the contact zone reduces significantly, hence the adsorption strength of the already adsorbed film determines the lubricity. The strength of this film was assessed in stage III by obtaining COFs after the bulk emulsions were replaced with water. SEM images of the wear tracks on the discs were also obtained using Jeol JCM6000 SEM/EDS (Jeol Ltd.).

\section{Results and Discussion}

\subsection{Size Distribution of the Dispersed Droplets}

Changes of size distributions of the oil droplets over time indicate how stable the droplet dispersions are. Figure 1a,b compares the changes of droplet sizes with time in emulsions without and with $0.25 \mathrm{wt} \%$ NPs. Without NPs, two overlapped size distributions are observed with average sizes of $170 \mathrm{~nm}$ and $550 \mathrm{~nm}$ on day 0 (Figure 1a). After 14 days, two overlapped distributions enlarge and form distinct small and large groups of droplets with average $200 \mathrm{~nm}$ and $2790 \mathrm{~nm}$ sizes. After 28 days, aggregation of the droplets with an average size of $2500 \mathrm{~nm}$ is observed, which is thought to be due to attractive forces between the hydrophobic oil droplets resulting in the over-time coalescence of the fine droplets $[7,24]$. On the contrary, in presence of $0.25 \mathrm{wt} \% \mathrm{NPs}$, the dispersed oil droplets with a 220-nm average size remain stable for up to 28 days (Figure 1b). Similar size distributions are obtained in presence of $0.5 \mathrm{wt} \%$ and $0.75 \mathrm{wt} \% \mathrm{NPs}$ (not shown). We attribute this to the steric barriers rendered by the presence of NP shields on the droplets' surface [25].

With $0.1 \mathrm{wt} \% \mathrm{NPs}$, monodispersed droplets with an average size of $600 \mathrm{~nm}$ are obtained immediately after the preparation (Figure 1c). Increasing the NPs' mass fraction from $0.1 \mathrm{wt} \%$ to $0.25 \mathrm{wt} \%$ lowers the average droplet size to $220 \mathrm{~nm}$. When the NPs mass fraction is increased to $0.5 \mathrm{wt} \%$, adsorption of NPs on the droplets reaches the maximum plateau with a limited average droplets size $(\sim 260 \mathrm{~nm})$. This is attributed to the saturation of droplets' surface with NP shields in the presence of $0.5 \mathrm{wt} \% \mathrm{NPs}$. Excess NPs at above $0.5 \mathrm{wt} \%$ mass fraction contribute to the formation of NP agglomerates [15]. NP agglomerates are not stable within the emulsions and tend to sediment over time. This reduces the overall stability of the droplets, noted by high dispersity index $(\approx 0.89)$ of the emulsion with $1 \mathrm{wt} \%$ NPs only after 7 days (not shown). 

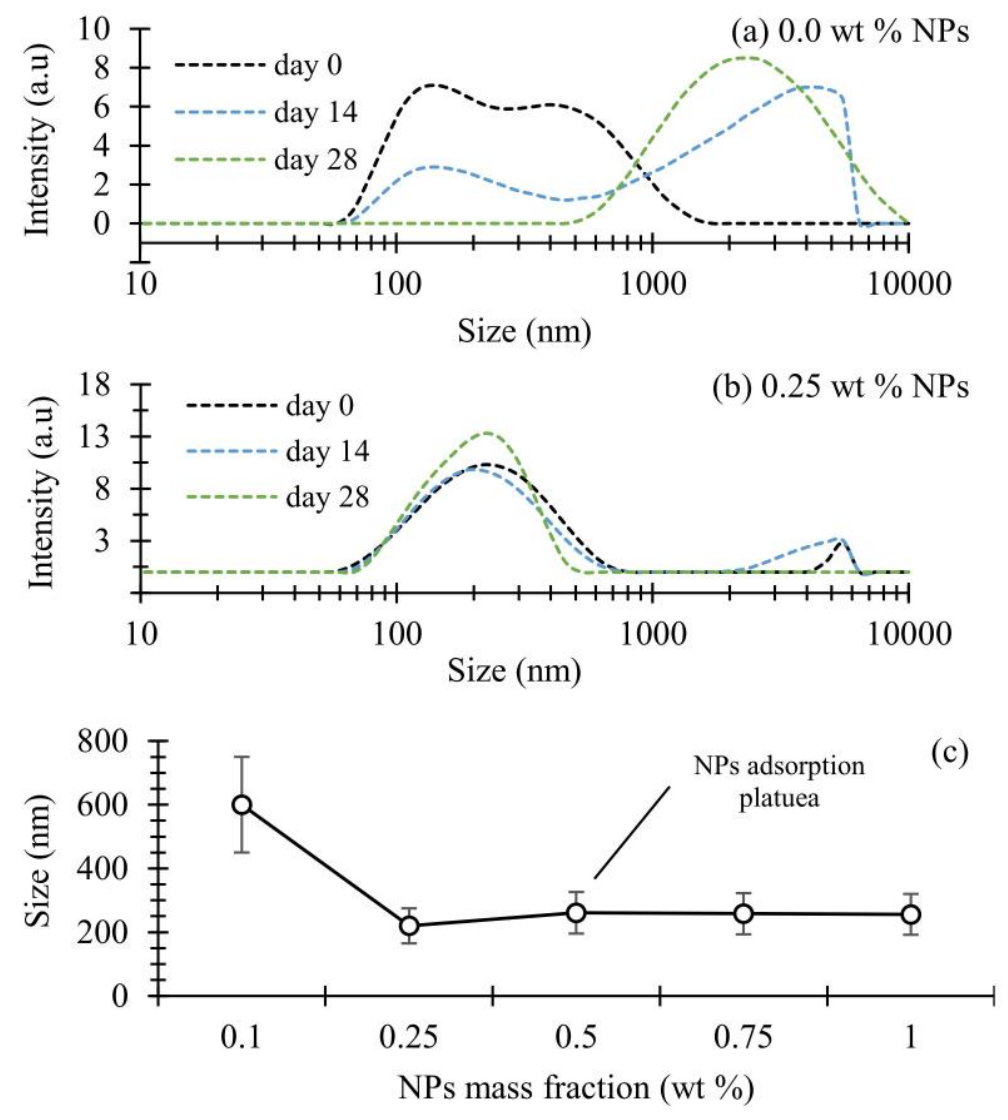

Figure 1. Over-time size distribution of oil droplets during 28 days (a) in emulsion without NPs; and (b) in emulsion with $0.25 \mathrm{wt} \% \mathrm{NPs}$; (c) average size of droplets in emulsions with $0.1 \mathrm{wt} \%-1 \mathrm{wt} \%$ NPs immediately after the preparation.

Polar vegetable oil droplets tend to attract NPs [26]. However, the adsorption of silica $\left(\mathrm{SiO}_{2}\right) \mathrm{NPs}$ on the oil droplets occurs at equilibrium with the dispersed free NPs, indicating the formation of NP agglomerates in emulsions even with a low amount of NPs [14,27]. Similar behaviour is expected for $\mathrm{SiO}_{2} / \mathrm{TiO}_{2} \mathrm{NPs}$. Therefore, the formation of NP agglomerates is expected regardless of the mass fraction of NPs. This is evidenced with $\sim 5.5 \mu \mathrm{m}$ sizes detected in the presence of all mass fractions of NPs (see Figure $1 \mathrm{~b}$ as an example), traced to the NPs by EDS mapping of Ti and Si elements. This is shown in Figure 2, indicating the tendency of NPs to from NP agglomerates in the aqueous phase of emulsions.
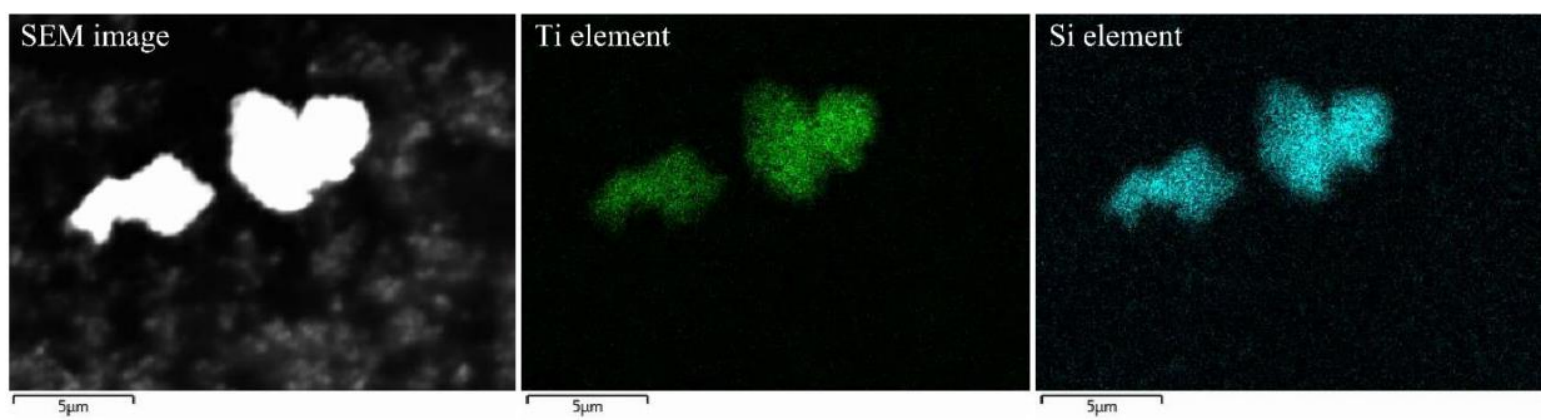

Figure 2. SEM image and EDS mapping of Ti and Si elements in NP agglomerates in emulsions with NPs (scale bars $5 \mu \mathrm{m}$ ). 


\subsection{UV-Vis Spectrophotometry Analysis}

Dispersion stability is inferred with UV-vis spectrophotometry. Figure 3a shows the absorbance spectra of the emulsions with different mass fractions of NPs immediately after the preparation. Peak wavelengths are determined where $\frac{\Delta \text { adsorption }}{\Delta \text { wavelength }}=0$ and are denoted by dashed lines. Wide absorbance peaks of emulsions indicate the multidisperse behaviour of droplets and NPs in the emulsions [28]. Without NPs, a peak at a small wavelength $(200.5 \mathrm{~nm})$ is obtained linked to the NP-free droplets. With $0.25 \mathrm{wt} \% \mathrm{NPs}$, a greater peak wavelength compared to the NP-free emulsion is observed at $243.5 \mathrm{~nm}$. This shift is attributed to a higher local density in the emulsion with NPs compared to the NP-free emulsion [29] by the virtue of adsorption of the NPs on the droplets' surface. Increasing the NPs' mass fraction to $0.5 \mathrm{wt} \%$ increases the adsorption of NPs on the droplets, which increases the absorbance intensity while the peak wavelength increases slightly to $251 \mathrm{~nm}$. NPs' adsorption on droplets reaches the maximum plateau at $0.5 \mathrm{wt} \%$ while further increasing the NPs' mass fraction results in the formation of NP agglomerates only. This is inferred by a significant increase in the absorbance peak wavelength to $306 \mathrm{~nm}$ with $1 \mathrm{wt} \% \mathrm{NPs}[28,30]$. Moreover, flattening in the absorbance intensity is observed with $1 \mathrm{wt} \%$ NPs below $300 \mathrm{~nm}$. This is due to the full adsorption of UV in the wavelength range of 200-300 $\mathrm{nm}$ by the NP agglomerates.

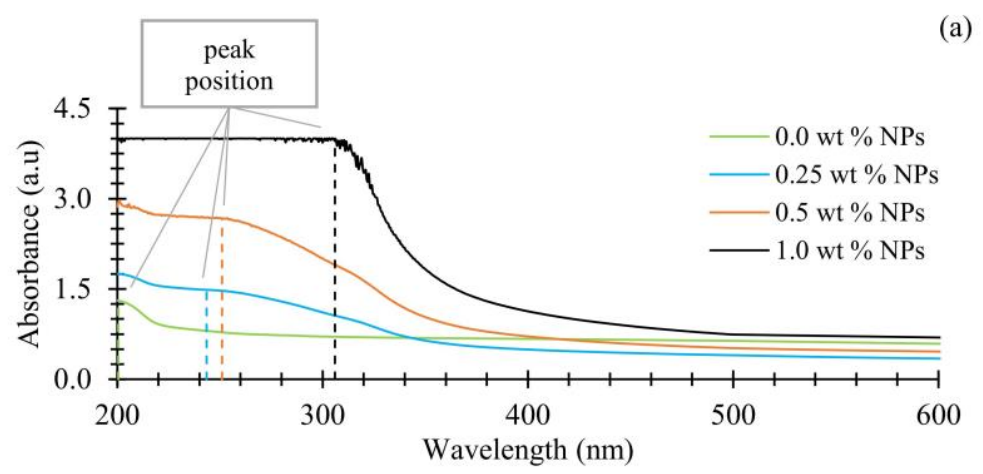

(b)

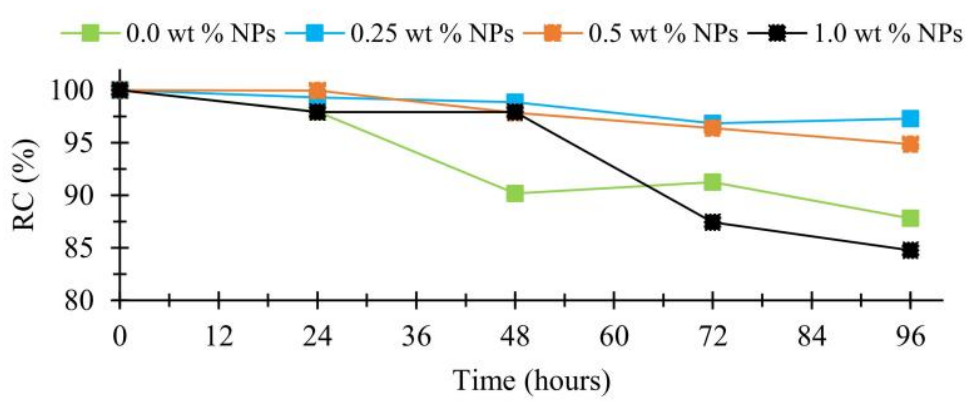

Figure 3. (a) UV-vis absorbance spectra of emulsions with $0 \mathrm{wt} \%-1 \mathrm{wt} \%$ NPs (peak wavelengths are shown by dashed lines); and (b) relative concentration $(R C)$ within $96 \mathrm{~h}$ after the preparation.

Relative concentration $(R C)$ is used to assess the over-time dispersion stability of the droplets (Figure $3 b) . R C$ is defined as the ratio of absorbance intensity to the corresponding initial value obtained after the preparation [31]. For instance, $100 \% R C$ indicates stable initial dispersions. Figure $3 \mathrm{~b}$ shows relatively high stability ( $R C>95 \%$ ) of the emulsions with $0.25 \mathrm{wt} \%$ and $0.5 \mathrm{wt} \%$ NPs for up to $96 \mathrm{~h}$, indicating the formation of stable droplets. On the other hand, the NP-free emulsion shows a $10 \%$ reduction in $R C$ within $48 \mathrm{~h}$. Interestingly, with excess NPs ( $1 \mathrm{wt} \%), R C$ remains at above $95 \%$ for $48 \mathrm{~h}$, then decreases to $87 \%$ and $84 \%$ after 72 and $96 \mathrm{~h}$, respectively. This indicates the degradation of the 
emulsion after $72 \mathrm{~h}$, which is related to the propensity of excess NPs to form sedimenting $\mu \mathrm{m}$-sized NP agglomerates which consequently lower the dispersion stability of the droplets.

\subsection{CLSM Analysis of Emulsions}

To explain the above observation, we hypothesize that $\mathrm{TiO}_{2} / \mathrm{SiO}_{2} \mathrm{NPs}$ form anticoalescing shell-like NP layers on the droplets' surface $[8,11,21]$. To examine this, confocal laser scanning microscopy (CLSM) was used. Soybean oil and $\mathrm{TiO}_{2} / \mathrm{SiO}_{2} \mathrm{NPs}$ are nonfluorescent. In order to visualise the NPs, Rhodamine B fluorescence dye was used $\left(\mathrm{SiO}_{2} \mathrm{NPs}\right.$ attract Rhodamine $\mathrm{B}$ dye in water due to electrostatic interactions [22]). Figure 4 shows the bright-field and CLSM images of the NP-free emulsion immediately after the preparation (day 0) and after 7 days. On day 0, NP-free droplets with varying sizes were detected in the dye solution (Figure $4 a, b$ ). This confirms the initial stability of NP-free droplets of ultrasonically prepared emulsions. Larger droplets are observed after 7 days (Figure 4c,d), indicating the aggregation of fine droplets due to the strong attraction forces between the bare hydrophobic oil droplets. This agrees with previous results indicating that the average size of NP-free droplets increases over time in absence of coalescence barriers.
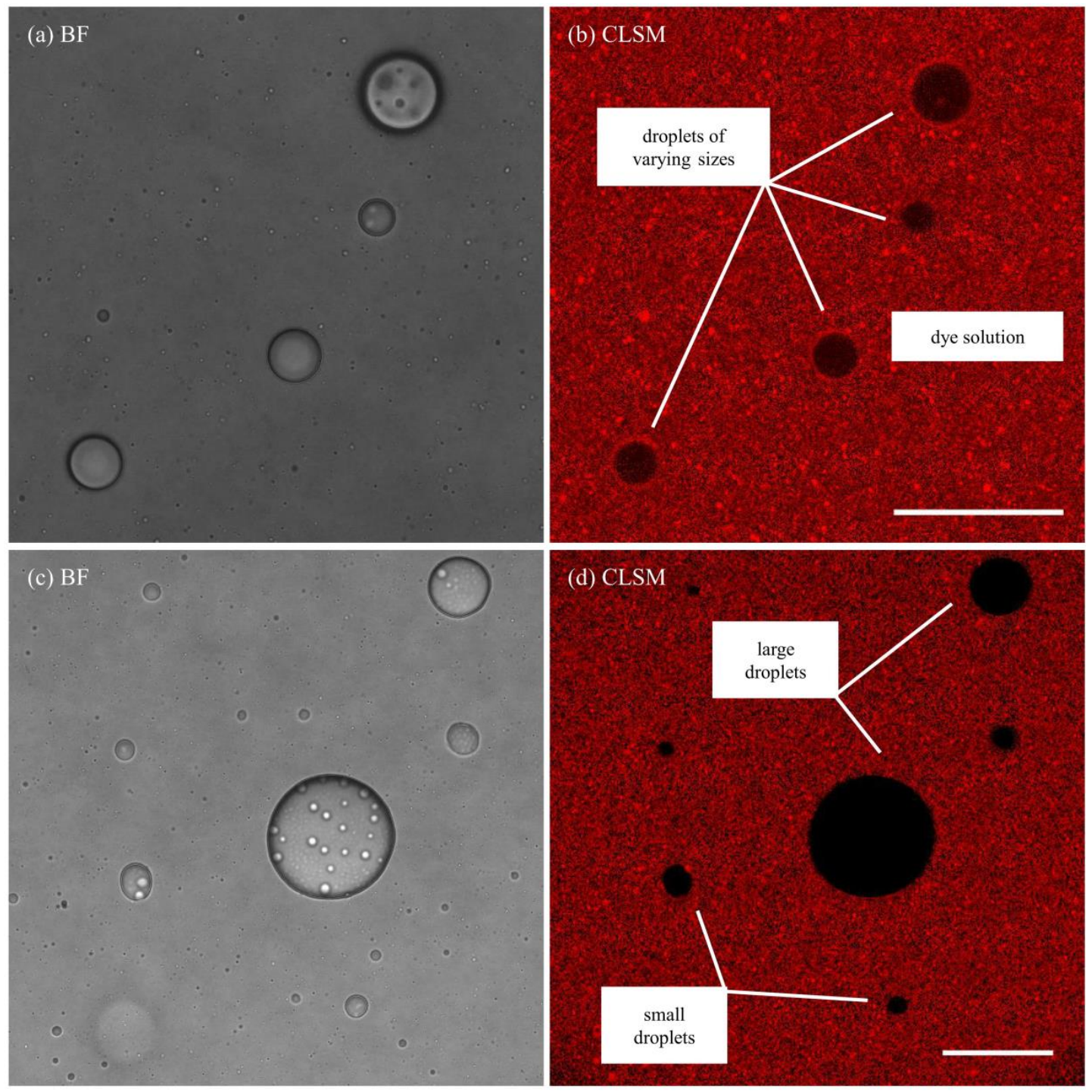

Figure 4. Corresponding bright-field (BF) and confocal laser scanning microscopy (CLSM) images of NP-free droplets in $0.0001 \mathrm{wt} \%$ Rhodamine B dye solution, (a,b) after the preparation (day 0); (c,d) after 7 days (scale bars $5 \mu \mathrm{m}$ ). 
Figure 5 shows the CLSM images of emulsions with $0.25 \mathrm{wt} \%$ and $0.5 \mathrm{wt} \%$ NPs on day 0 . In the presence of NPs, formation of anticoalescing NP shields on the droplets' surface is expected. This is confirmed by tracing the Rhodamine B dye attached to the NPs to the oil/water interface of the droplets. However, these shielding layers appear different in $0.25 \mathrm{wt} \%$ and $0.5 \mathrm{wt} \%$ NPs. When the surface of the droplets is saturated with NPs at $0.5 \mathrm{wt} \%$ mass fraction (Figure $5 \mathrm{~b}$ ), the NP-shielded droplets are dispersed uniformly in the emulsion. On the contrary, with $0.25 \mathrm{wt} \%$ NPs, large droplets appear to have the tendency to attract other droplets but still retain their stability (Figure 5a). This is related to the intensity of NP shields on the droplets' surface that determines the extent of stability [32].

Individual oil droplets in emulsions with $0.25 \mathrm{wt} \%$ and $0.5 \mathrm{wt} \%$ NPs were further investigated with CLSM imaging immediately after the preparation (Figure 6, background noise is reduced). With $0.5 \mathrm{wt} \%$ NPs, uniform coverage of the droplets with NPs is observed (Figure 6b), which is enough to stabilise the droplets in the emulsion. However, $0.25 \mathrm{wt} \%$ mass fraction of NPs is below the required amount of NPs for full coverage of all the droplets with NPs (see Figure 1c). Therefore, with $0.25 \mathrm{wt} \%$ NPs, the surface of some droplets remains partially covered with NPs (Figure 6a) due to the shortage of the NP supply. This promotes initial partial coverage of some droplets with NPs below the required mass fraction. Therefore, with 0.25 wt \% NPs, two size-dependent pathways for the stabilisation of droplets are proposed. With initially fully covered droplets, uniform coverage of the droplets with NPs results in good dispersion stability owing to the effectiveness of NP shields on the droplets' surface. On the contrary, initially partially covered droplets with $0.25 \mathrm{wt} \% \mathrm{NPs}$ are hypothesised to undergo limited coalescence and form larger droplets (thus reduce the overall droplets/water interfacial area) until an equilibrium is reached where the total droplets/water interfacial area can be stabilised with available NPs [33]. At this state, as the partially covered droplets approach other droplets, short-ranged repulsion caused by the partially absorbed NP shields on the droplets increases and improves the stability at close proximity. This is due to the strong and irreversible adsorption of NPs on the droplets' surface, especially on the large droplets [12,14]. Therefore, the mechanism by which the stability of the droplets is provided is related to the overall droplets/water interfacial area (which is droplet-size and preparation-energy dependent [1]) and the availability of an adequate quantity of NPs in the aqueous phase.

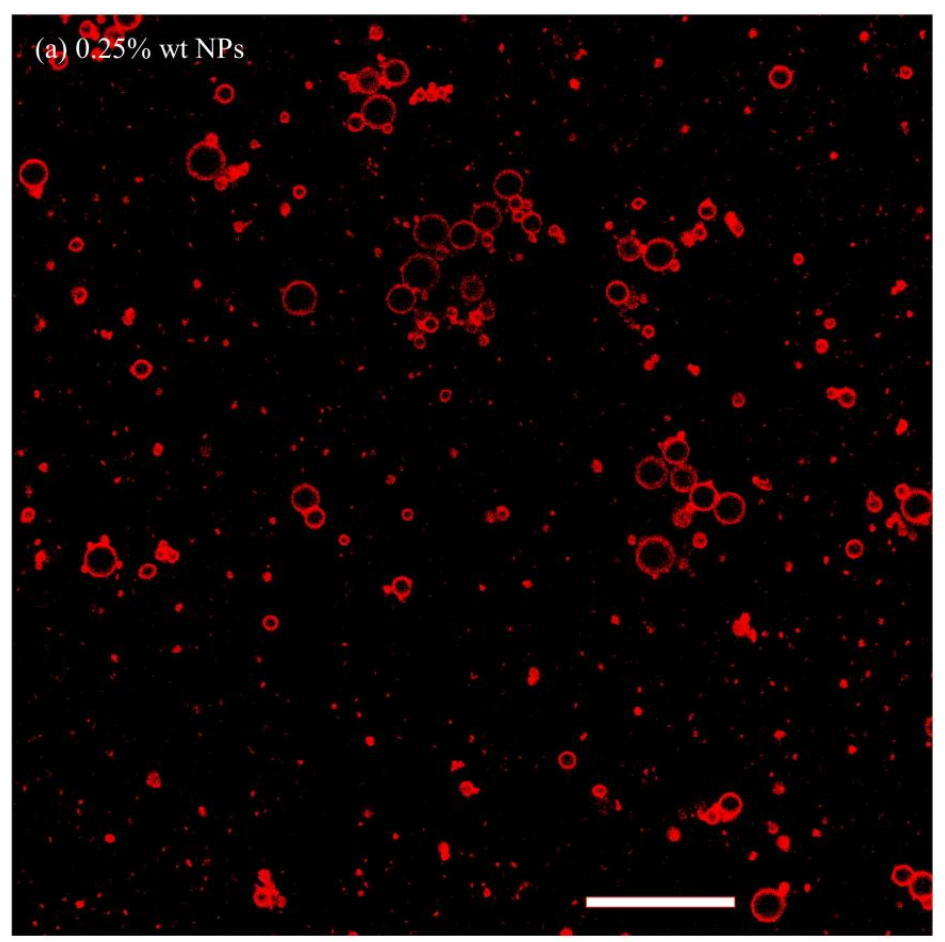

Figure 5. Cont. 


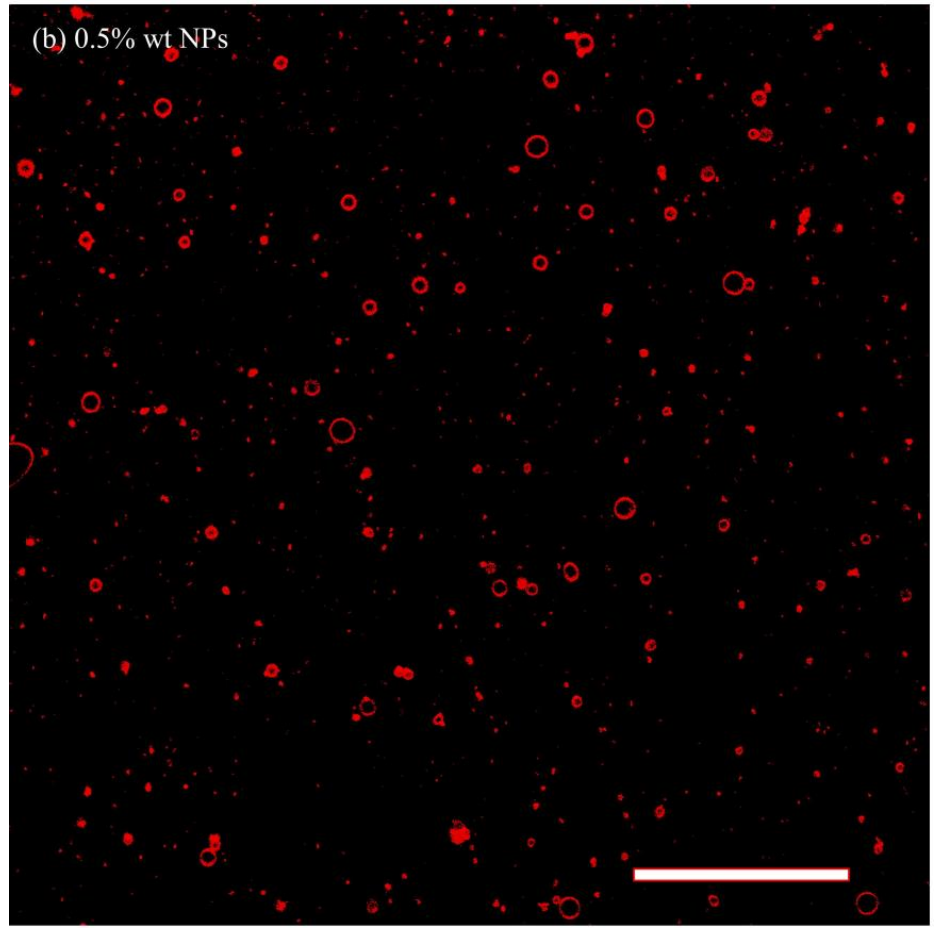

Figure 5. Confocal laser scanning microscopy (CLSM) images of emulsions after the preparation with (a) $0.25 \mathrm{wt} \%$; and (b) $0.5 \mathrm{wt} \% \mathrm{NPs}$ (scale bars $10 \mu \mathrm{m}$ ).

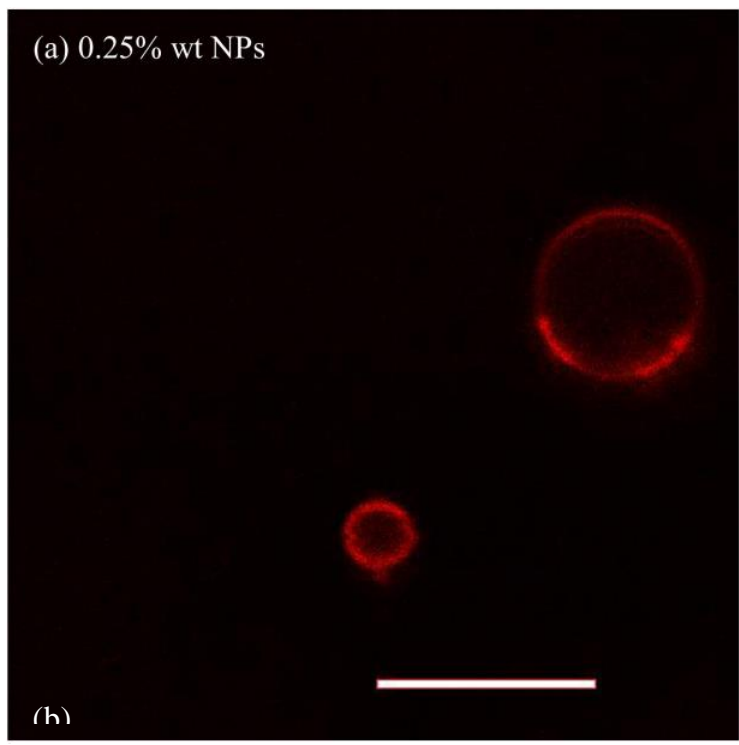

(b) $0.5 \%$ wt NPs

Figure 6. Confocal laser scanning microscopy (CLSM) images of emulsions after the preparation with (a) $0.25 \mathrm{wt} \%$; and (b) $0.5 \mathrm{wt} \%$ NPs (scale bars $3 \mu \mathrm{m}$ ).

\subsection{Friction and Wear}

It was observed that both $0.25 \mathrm{wt} \%$ and $0.5 \mathrm{wt} \%$ mass fractions of NPs can provide stability for the emulsions in which the full coverage of droplets occurs with the latter. However, the adsorption of $\mathrm{TiO}_{2} / \mathrm{SiO}_{2} \mathrm{NPs}$ on the droplets' surface is in equilibrium with the NP agglomerates in the aqueous phase, the presence of which is detrimental to lubricity. To examine this, friction tests were designed with emulsions having $0 \mathrm{wt} \%, 0.25 \mathrm{wt} \%$, and $0.5 \mathrm{wt} \%$ NPs (on day 0 ) and the results are shown 
in Figure 7. Water lubrication results in COF $\approx 0.48$ (stage I). By introducing emulsions in stage II, COF reduces significantly for all emulsions. The least friction coefficient is obtained without NPs $(C O F \approx 0.11)$ due to the formation of a tribofilm on the surface owing to the adsorption of fatty acid films. COF increases to 0.13 with 0.25 wt \% NPs, postulating the detrimental effect of NPs on the film-forming capability of the oil droplets [21]. With $0.5 \mathrm{wt} \%$ NPs COF further increases to 0.15 due to the abrasion of NPs between the surfaces. After replacing the emulsions with water (stage III), the film formed by the NP-free emulsion remains intact on the surface, as evidenced by the slight increase in COF to 0.13. On the other hand, replacing the emulsions having $0.25 \mathrm{wt} \%$ and $0.5 \mathrm{wt} \%$ NPs with water increases COF significantly. Therefore, with NPs, the strength of the film formed on the surface reduces, as evidenced by the increased COFs by replacing the bulk emulsions with water. This suggests cleaner friction surfaces with less oil residue after the lubrication by rinsing the surfaces with water.

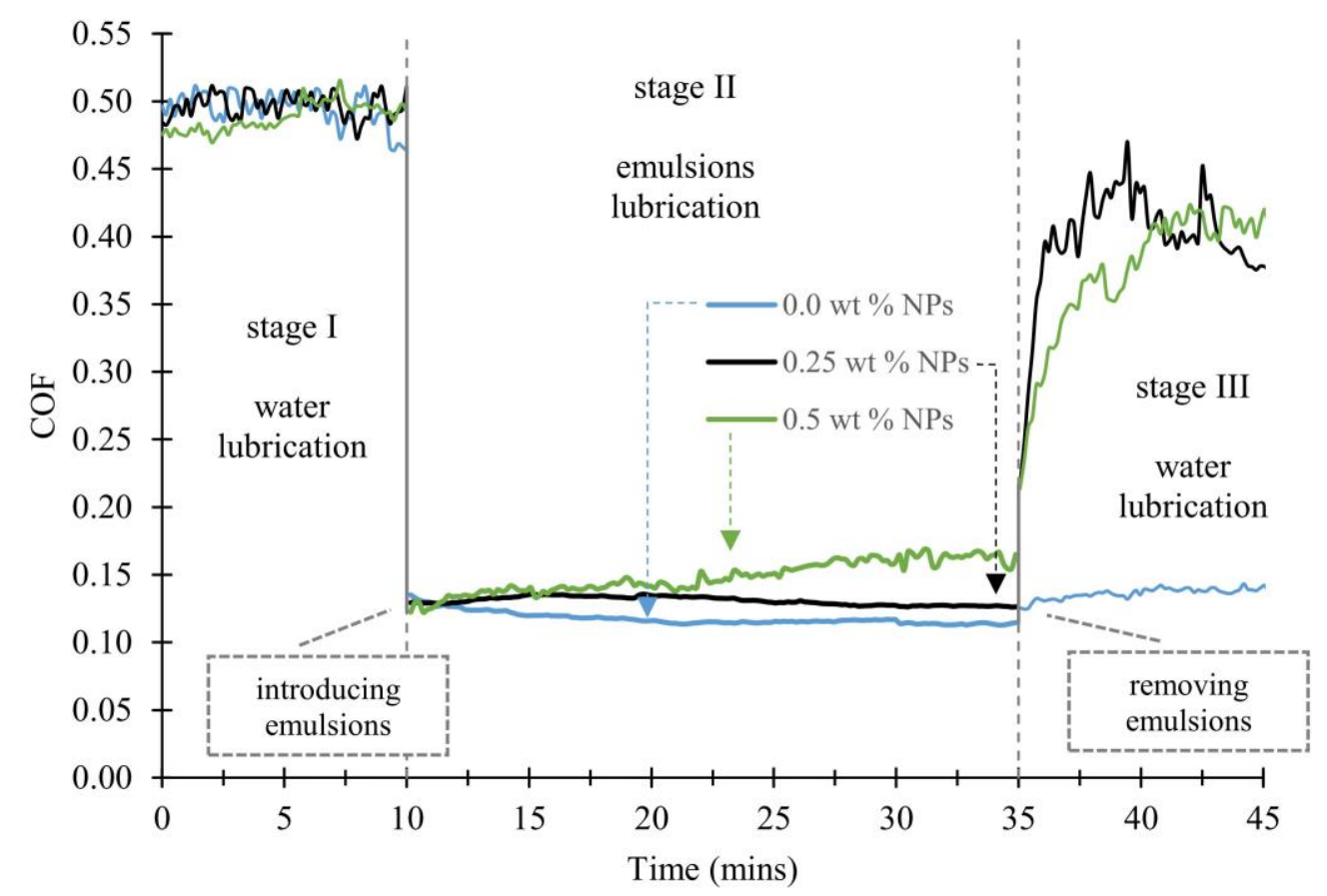

Figure 7. COF traces during water-emulsion-water lubrication processes: "stage I": water lubrication; "stage II": emulsions with $0 \mathrm{wt} \%, 0.25 \mathrm{wt} \%$, and $0.5 \mathrm{wt} \%$ NPs lubrication; and "stage III": water lubrication. Different stages are separated by dashed lines.

SEM images of wear tracks on the respective discs of friction tests are shown in Figure 8 . In spite of the low friction coefficient without NPs, wide furrows, fractures, and signs of plastic deformation are observed on the surface lubricated without the NPs (Figure 8a,b), indicating a dominant two-body abrasive wear due to high asperity contacts [34]. Wear reduces in presence of $0.25 \mathrm{wt} \%$ NPs, where mild scuffing grooves alongside the sliding direction are observed (Figure $8 \mathrm{c}, \mathrm{d}$ ). This is attributed to the entrapped NPs within the contact zone and in between the surfaces. These entrapped NPs work as rigid third bodies between the surfaces, mend the surface, and change the wear mechanism from abrasive two-body to mild three-body. This promotes a lower wear rate in presence of 0.25 wt $\%$ NPs compared to the latter $[35,36]$. 

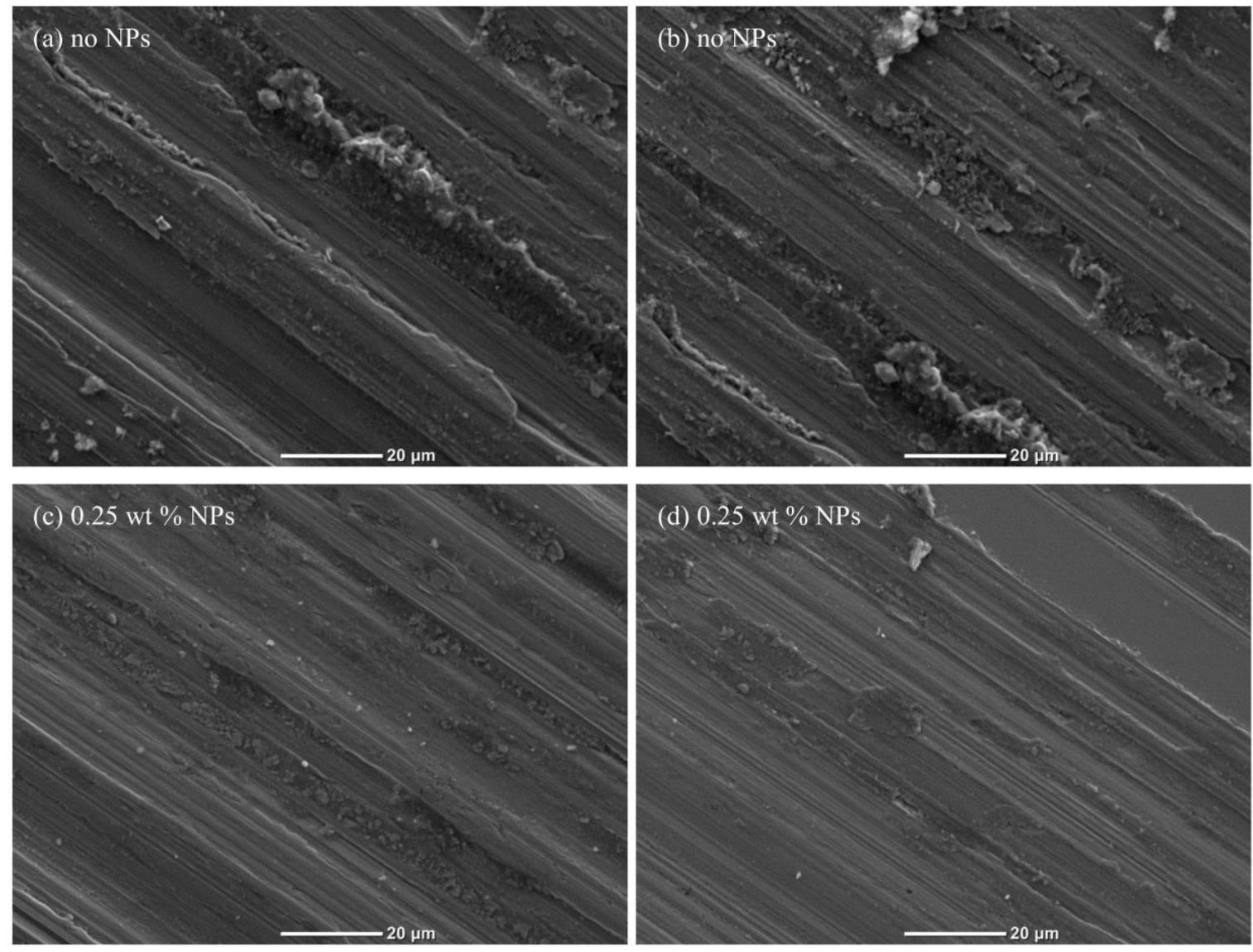

Figure 8. SEM images of the wear tracks on discs lubricated with $(\mathbf{a}, \mathbf{b})$ emulsion without NPs; (c,d) emulsion with $0.25 \mathrm{wt} \% \mathrm{NPs}$.

\section{Conclusions}

The dispersion stability and lubricity of soybean oil droplets in $\mathrm{VO} / \mathrm{W}$ emulsions with varying mass fractions of $\mathrm{TiO}_{2} / \mathrm{SiO}_{2} \mathrm{NPs}$ were investigated. The dispersion stability of the droplets is attributed to the formation of partial/full anticoalescing NP shields on the oil/water interface of the droplets. With $1 \mathrm{vol} \%$ soybean oil, $0.5 \mathrm{wt} \%$ NPs result in full coverage of the droplets with NPs providing a shielding layer around the droplets against coalescence. $0.25 \mathrm{wt} \%$ NPs can also provide stability for the droplets despite the partial coverage of the droplets at $0.25 \mathrm{wt} \%$ mass fraction. This indicates two size-dependent stabilisation pathways for droplets in the presence of a low quantity of NPs. Fully covered droplets have better and more uniform NP shields on the surface and thus preserve their fine size. Partially covered droplets coalesce initially until an equilibrium is reached at which available NPs can stabilise the total droplets/water interfacial area due to the strong adsorption of NPs on the droplets' surface and the close-range repulsion forces between them. NP agglomerates degrade over time and reduce the overall stability of droplets especially in high mass fractions of NPs (1 wt \%). Despite the small increase in COF with NPs, the presence of $0.25 \mathrm{wt} \%$ NPs improves wear protection due to the changed wear mechanism from two-body to mild three-body. The presence of NPs also promotes less oil residue on the surface after the lubrication process, which, from the cleanliness point of view, is favourable in many applications.

Author Contributions: Conceptualization, R.T. and B.K.; Data curation, R.T.; Funding acquisition, B.K., H.Z. and A.K.T.; Investigation, R.T.; Methodology, R.T. and B.K.; Resources, B.K., H.Z. and A.K.T.; Supervision, B.K.; Writing—original draft, R.T.; Writing—review \& editing, R.T., B.K., H.Z. and A.K.T.

Conflicts of Interest: The authors declare no conflict of interest. 


\section{References}

1. Taheri, R.; Kosasih, B.; Zhu, H.; Tieu, A. Surface film adsorption and lubricity of soybean oil in water emulsion and triblock copolymer solution: A comparative study. Lubricants 2017, 5, 1. [CrossRef]

2. Adhvaryu, A.; Erhan, S.; Perez, J. Tribological studies of thermally and chemically modified vegetable oils for use as environmentally friendly lubricants. Wear 2004, 257, 359-367. [CrossRef]

3. Alves, S.; Barros, B.; Trajano, M.; Ribeiro, K.; Moura, E. Tribological behavior of vegetable oil-based lubricants with nanoparticles of oxides in boundary lubrication conditions. Tribol. Int. 2013, 65, 28-36. [CrossRef]

4. Doll, K.M.; Sharma, B.K. Emulsification of Chemically Modified Vegetable Oils for Lubricant Use. J. Surfactants Deterg. 2011, 14, 131-138. [CrossRef]

5. Pashley, R.M. Effect of Degassing on the Formation and Stability of Surfactant-Free Emulsions and Fine Teflon Dispersions. J. Phys. Chem. B 2003, 107, 1714-1720. [CrossRef]

6. Israelachvili, J.; Pashley, R. The hydrophobic interaction is long range, decaying exponentially with distance. Nature 1985, 300, 341-342. [CrossRef]

7. Kamogawa, K.; Akatsuka, H.; Matsumoto, M.; Yokoyama, S.; Sakai, T.; Sakai, H.; Abe, M. Surfactant-free $\mathrm{O} / \mathrm{W}$ emulsion formation of oleic acid and its esters with ultrasonic dispersion. Colloids Surf. A 2001, 180, 41-53. [CrossRef]

8. Ridel, L.; Bolzinger, A.; Delepine, N.G.; Dugas, P.Y.; Chevalier, Y. Pickering emulsions stabilized by charged nanoparticles. Soft Matter 2016, 12, 7564-7576. [CrossRef] [PubMed]

9. Dai, W.; Kheireddin, B.; Gao, H.; Liang, H. Roles of nanoparticles in oil lubrication. Tribol. Int. 2016, 102, 88-98. [CrossRef]

10. Binks, B.P.; Lumsdon, S.O. Stability of oil-in-water emulsions stabilised by silica particles. Phys. Chem. Chem. Phys. 1999, 1, 3007-3016. [CrossRef]

11. Dickinson, E. Food emulsions and foams: Stabilization by particles. Curr. Opin. Colloid Interface Sci. 2010, 15, 40-49. [CrossRef]

12. Chevalier, Y.; Bolzinger, M.-A. Emulsions stabilized with solid nanoparticles: Pickering emulsions. Colloids Surf. A 2013, 439, 23-34. [CrossRef]

13. Binks, B.P.; Lumsdon, S.O. Catastrophic Phase Inversion of Water-in-Oil Emulsions Stabilized by Hydrophobic Silica. Langmuir 2000, 16, 2539-2547. [CrossRef]

14. Simovic, S.; Prestidge, C. Hydrophilic Silica Nanoparticles at PDMS Droplet-Water Interface. Langmuir 2003, 19, 3785-3792. [CrossRef]

15. Frelichowska, J.; Bolzinger, M.-A.; Chevalier, Y. Effects of solid particle content on properties of o/w Pickering emulsions. J. Colloid Interface Sci. 2010, 351, 348-356. [CrossRef] [PubMed]

16. Hunter, T.N.; Pugh, R.J.; Franks, G.V.; Jameson, G.J. The role of particles in stabilising foams and emulsions. Adv. Colloid Interface Sci. 2008, 137, 57-81. [CrossRef] [PubMed]

17. Gao, Y.; Chen, G.; Oli, Y.; Zhang, Z.; Xue, Q. Study on tribological properties of oleic acid-modified $\mathrm{TiO}_{2}$ nanoparticle in water. Wear 2002, 252, 454-458. [CrossRef]

18. Wu, Y.; Kao, M. Using $\mathrm{TiO}_{2}$ nanofluid additive for engine lubrication oil. Ind. Lubr. Tribol. 2011, 63, 440-445. [CrossRef]

19. Riazian, M.; Montazeri, N.; Biazar, E. Nano Structural Properties of $\mathrm{TiO}_{2}-\mathrm{SiO}_{2}$. Orient. J. Chem. 2011, $27,903-910$.

20. Wei, D.; Dave, R.; Pfeffer, R. Mixing and characterization of nanosized powders: An assessment of different techniques. J. Nanopart. Res. 2002, 4, 21-41. [CrossRef]

21. Taheri, R.; Kosasih, B.; Zhu, H.; Tieu, A.K. Suspension stability and lubricity of eco-friendly vegetable oil-in-water emulsions stabilised by $\mathrm{TiSiO}_{4}$ nanoparticles. In Proceedings of the 6th World Tribology Congress, Beijing, China, 17-22 September 2017.

22. Vashisth, C.; Whitby, C.P.; Fornasiero, D.; Ralston, J. Interfacial displacement of nanoparticles by surfactant molecules in emulsions. J. Colloid Interface Sci. 2010, 349, 537-543. [CrossRef] [PubMed]

23. Taheri, R.; Kosasih, B.; Zhu, H.; Tieu, A.K. Phase behaviour and lubricity of aqueous PEO-PPO-PEO and PPO-PEO-PPO triblock copolymer solutions. Tribol. Trans. 2017, 60, 460-468. [CrossRef]

24. Fox, N.; Stachowiak, G. Vegetable oil-based lubricants-A review of oxidation. Tribol. Int. 2007, 40, 1035-1046. [CrossRef]

25. Aveyard, R.; Binks, B.; Clint, J. Emulsions stabilised solely by colloidal particles. Adv. Colloid Interface Sci. 2003, 100, 503-546. [CrossRef] 
26. Binks, B.; Whitby, C. Nanoparticle silica-stabilised oil-in-water emulsions: Improving emulsion stability. Colloids Surf. A 2005, 253, 105-115. [CrossRef]

27. Simovic, S.; Prestidge, C.A. Adsorption of Hydrophobic Silica Nanoparticles at the PDMS Droplet-Water Interface. Langmuir 2003, 19, 8364-8370. [CrossRef]

28. Sharma, P.; Baek, I.-H.; Cho, T.; Park, S.; Lee, K.B. Enhancement of thermal conductivity of ethylene glycol based silver nanofluids. Powder Technol. 2011, 208, 7-19. [CrossRef]

29. Lacava, J.; Ouali, A.A.; Raillard, B.; Kraus, T. On the behaviour of nanoparticles in oil-in-water emulsions with different surfactants. Soft Matter 2014, 10, 1696-1704. [CrossRef] [PubMed]

30. Lee, M.H.; Oh, S.G.; Suh, K.D.; Kim, D.G.; Sohn, D. Preparation of silver nanoparticles in hexagonal phase formed by nonionic Triton X-100 surfactant. Colloids Surf. A 2002, 210, 49-60. [CrossRef]

31. Zareh-Desari, B.; Davoodi, B. Assessing the lubrication performance of vegetable oil-based nano-lubricants for environmentally conscious metal forming processes. J. Clean. Prod. 2016, 135, 1198-1209. [CrossRef]

32. Katepalli, H.; Bose, A. Response of Surfactant Stabilized Oil-in-Water Emulsions to the Addition of Particles in an Aqueous Suspensio. Langmuir 2014, 30, 12736-12742. [CrossRef] [PubMed]

33. Arditty, S.; Whitby, C.P.; Binks, B.P.; Schmitt, V.; Leal-Calderon, F. Some general features of limited coalescence in solid-stabilized emulsions. Eur. Phys. J. E 2003, 11, 273-281. [CrossRef] [PubMed]

34. Moore, M.A. A review of two body abrasive wear. Wear 1974, 27, 1-17. [CrossRef]

35. Peng, D.X.; Kang, Y.; Hwang, R.M.; Shyr, S.S.; Chang, Y.P. Tribological properties of diamond and $\mathrm{SiO}_{2}$ nanoparticles added in paraffin. Tribol. Int. 2009, 42, 911-917. [CrossRef]

36. Trezona, R.I.; Allsopp, D.N.; Hutchings, I.M. Transitions between two-body and three-body abrasive wear: Influence of test conditions in the microscale abrasive wear test. Wear 1999, 225-229, 205-214. [CrossRef]

(C) 2018 by the authors. Licensee MDPI, Basel, Switzerland. This article is an open access article distributed under the terms and conditions of the Creative Commons Attribution (CC BY) license (http:/ / creativecommons.org/licenses/by/4.0/). 